\title{
Online laboratories and Cross-Reality in engineering education
}

COVID-19 has compelled educators to rapidly transition to online learning methods. This shift is particularly challenging for instructors whose courses involve his res laboratory instrutio In his research, Dr Dominik in the Engineering Education Transformations Institute at the University of Georgia, has been focusing on online laboratories and Cross-Reality learning spaces in engineering education for over a decade. Collaborating with researchers from the withernational communty of Dr May has been involved in the digital instructional design of and respective educational research on courses for mechanical, electrical, biological, civil and computer engineers. His work provides an environment for collaborative engineering lab work for students irrespective of
their physical location.

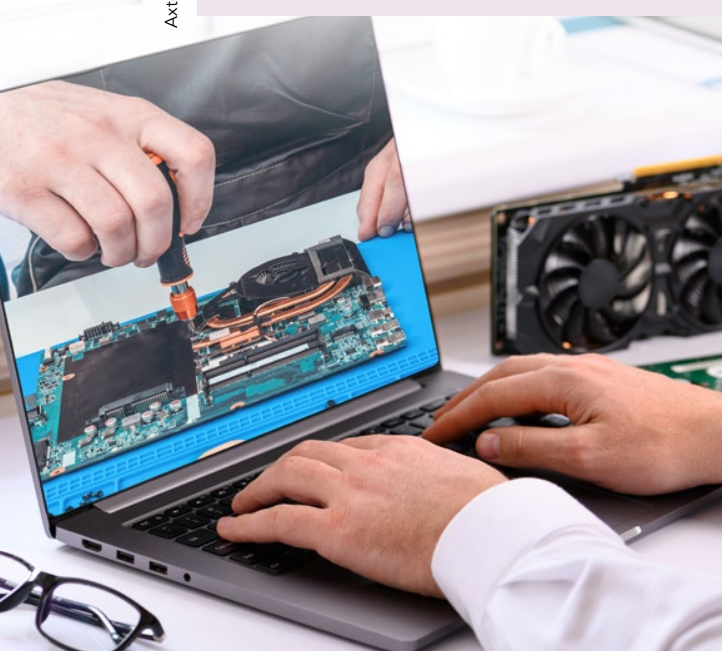
he COVID-19 pandemic has
compelled educators to hastily
move to online instruction thods. While this shift is difficult for any subject, it is particularly challenging involve hands-on laboratory instruction. This occurs in many STEM courses.

Research being carried out by $\mathrm{Dr}$ Dominik May, an Assistant Professo in the Engineering Education Transformations Institute at the University of Georgia, focuses on online laboratories and Cross-Reality learning spaces in engineering education. Dr May explains that he uses Cross-Reality learning spaces and labs as a descriptive umbrella term that covers all online laboratory solutions that use remote reality, virtual reality, and mixed reality.

\section{KEY AREAS}

Dr May's research focuses on three key areas that are in line with the higher education. Firstly, he explores the integration of different online laboratory solutions with virtual. experimentation activities that form part of the engineering curriculum. and investigates how they promote student engagement and studen

Secondly, he examines the assessment and evaluation of virtua experimentation activities aimed at improving the students' learning experience in Cross-Reality learning spaces, specifically during on
Thirdly, he investigates virtual experimentation activities designed to develop a fundamental understanding of cognitive and affective factors experience tin ${ }^{2}$ students' learning spaces, again porticuly during online laboratory-based instruction.

Dr May believes that "face-to-face instruction and online instruction should never be seen as 'either-or' things, but it is important to examine, define, and combine the strengths of both worlds for the overall learning experience ". His studies and work from other researchers in the field have shown that hands-on experimentation activities often focus on developing knowledge and procedural skills rather than the development of competencies to solve workplace problems. Furthermore, they require and promote different skills and competencies when compared with ands on and vitul experimentation learning activities however can be combined according to their individual strengths and intended learning outcomes for a particular lab activity. Moreover, they can be tailored to the preferences or needs of the individual student, as well as the school's infrastructure and resources.

\section{LABORATORIES AS A TEACHING} AND LEARNING ENVIRONMENT Dr May describes how the use of laboratories as a teaching and learning environment has been an essential part frience and engineering education at universities since the very beginning Laboratories have a crucial role in both research-oriented and applicationbased study programs. He notes that to as a teaching and learning location, however, there must be a specific competence-oriented approach to learning in laboratories if the mere reproduction of specialist knowledg and skills is to be avoided. While research-based learning is the central paradigm of laboratory teaching, genuine competence development is essential to promote students' employability in science and industry.

\section{CROSS-REALITY}

Online or Cross-Reality laboratories encompass all types of digitally or onlinesupported teaching-learning laborato Cross-Reality labs employ emerging Cross eality. Augmented reality labs can involve, for example, experimental se that use augmented reality to display reatime data such as temperature or pressure directly on the test device. Cross-Reality technologies involve 3D models and simulations using physical, virtual, and immersive platforms and offer particular innovation potential for engineering education. Dr May's research consists in comparing real, remotely accessible and virtual instrumentation, specifically in the context of STEM education, and examining their impact on learning and communication $p$

\section{sociotechnical issues.}

\section{THE EAGER PROJECT}

One of Dr May's foremost engineering to-face to exclusively online engineering laboratory classes in an Electrical and Computer Engineering program', whic is funded by the US National Science Foundation (award \#2032802). This project examines the impact of using only online laboratory modules in an engineering laboratory course beyond COVID-19. Current work involves exploring the rapid switch from face-to-face experimentation to online laboratories from three different perspectives. the perspective of students taking Electrical Engineering and Computer Systems Engineering courses, Courses a the of faculy teaching such the own teaching habits, and the user

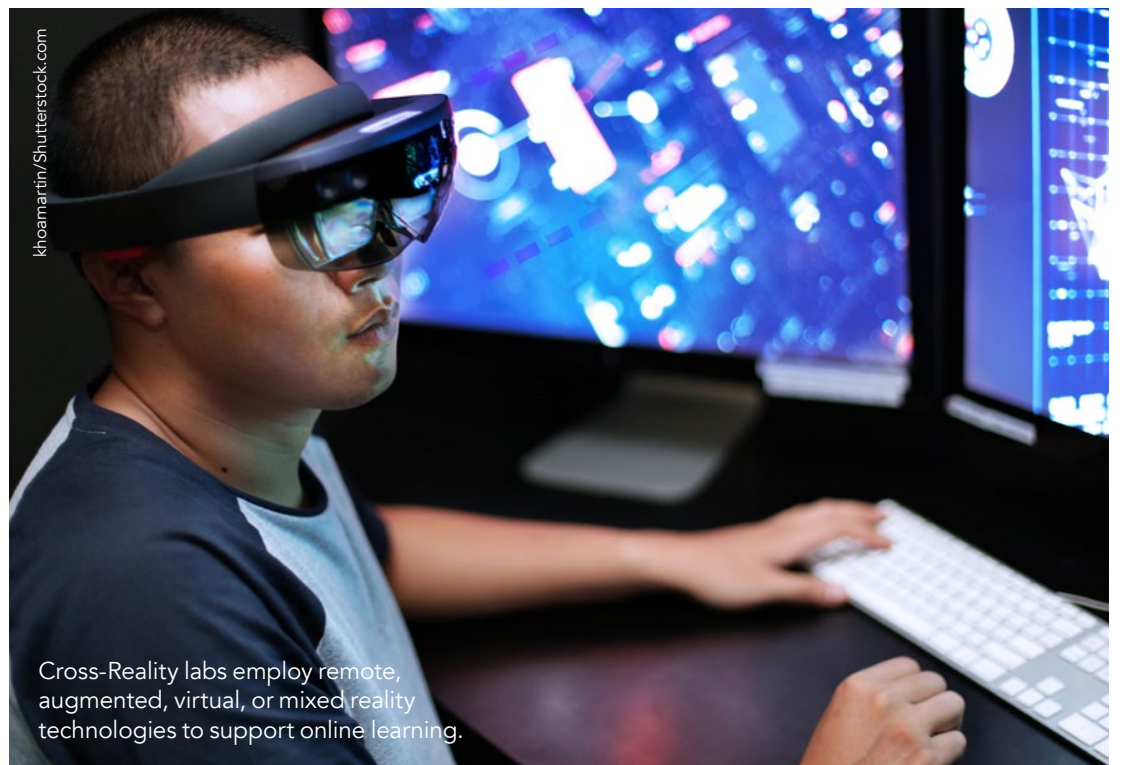

experience perspective describing how the online environment Bringing al three perspectives together is aruci to improve the instructional design in technology-enhanced lab-based engineering education.

LEARNING COMPATIBILITY Student interviews revealed several benefits of in-person labs. These included participating in the campus experience, immersed in the lab environment, and getting more practice with the equipme

\section{QUESTION AND INQUIRY} In online laboratory contexts, studen ts communicate with their professors or partners, particularly when they needed help. Clear communication and verbal instruction tend to happen naturally in face-to-face lab courses but require more deliberate planning during online instruction. Online students were more likely to access support if they knew that they could get help via Zoom calls or structured time to ask questions. Other comments from faculty and students revealed that online communication led to a more deliberate discussion,

Hands-on experimentation activities often focus on developing knowledge and procedural skills, rather than the development of competencies to solve workplace problems.

less time commuting and were able to work at their own pace and with respect to their own leanning needs. Online labs also propared them for future digital working home. They commented that working from home also allowed personal health safety during the pandemic. Some students found that using online labs exceeded her expectations as it was their growth in learning. and properly formulate the question. Moso, wh hout the time constraints sometimes present in face-to-face lab about their response.

PLANNING AND COORDINATION To execute the lab successfully, students had to ensure that the equipment worked so that they could complete time. They found that it was imperative 


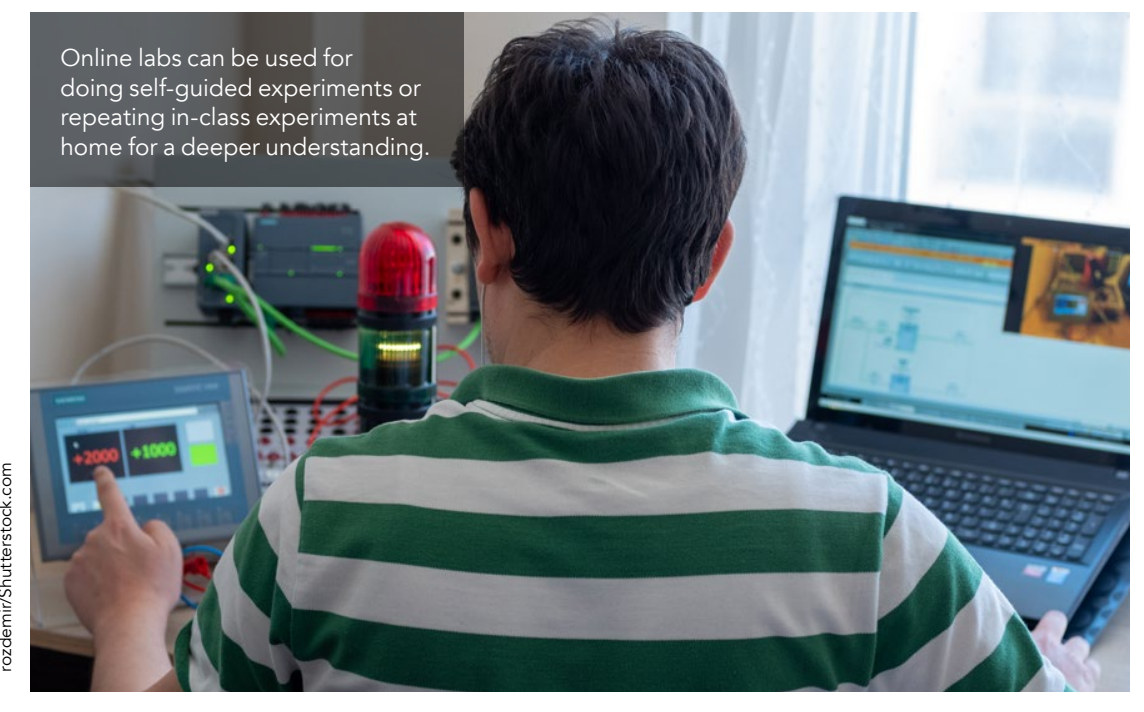

to remain organised and keep to the course schedule, which is more $\begin{array}{ll}\text { The research team collaborated with } \\ \text { is more } & \text { the remote laboratory platform and }\end{array}$ to face-to-face settings.

Dr May explains that for online lab courses to offer a comparable educational experience that inperson instruction affords, the same educational and curricular value of laboratories must be maintained taking advantage of the benefits offered by online education and online experimentation tools. As part of the project, he is carrying out a similar study from the instructors' perspective to determine how the deal with the rapid transition to exclusively online-based laboratory company LabsLand, used the circuits remole with the video conferencing platform Zoom, and examined the students' perception and academic performance in the online lab settings in compariso with their previous experience of the physical labs. LabsLand ${ }^{\circledast}$ is a longstanding partner in Dr May's research and offers a plattorm with many online fields in STEM education.

\section{FINDINGS}

Analysing the results revealed tha

The landscape of lab learning changed with the sudden transition from physical labs to online labs.

whether they resist or embrace these educational technologies.

\section{AN ONLINE REMOTE LAB STUDY} WITH LABSLAND ${ }^{\circ}$ AND ZOOM

Dr May has also been involved in a comparative study of an online remote lab using Zoom during COVID-19. The landscape of lab learning changed physical labs to online labs. This study involved using the remotely accessible version of a real electrical circuit lab environment for a class of 38 student
during the 2020 spring semester. experiments after a live session or in advance of an assessment. challenges of online labs and sugges lab interfaces unintuitive.
The researchers advise instructors to study the interface's quirks and be of time helping students deal with the Compared with physical labs, online labs student collaboration. At the beginning of the course, instructors are advised to discuss what effective real-world teamwork looks like, together with the build teamwork skills. Students need access to their instructors for help with labs should be structured to maximise students' ability to receive help from the instructional team. Following these for collaborative engineering lab work for students irrespective of their physica interaction and collostering social due to still existing technical constrains. It is of vital importance for future educational development and research in this field to include social interaction in online labs to avoid loosing this very learning experience.

INTERNATIONAL COLLABORATION Dr May is collaborating with colleagues within the University of Georgia as well as researchers from the international community of engineering education research, such as the International Association of Online Engineering and Education. He has been Engineering digital instructional design of courses for electrical biological civil and computer engineers. Moreover his work has led to the creation of the Engineering Innovative Teaching Lab Group at the University of Georgia.

\section{THE FUTURE OF}

ENGINEERING EDUCATION

DrMay's research addresses a critical

requirement that has been exemplified during the COVID-19 global health crisis with the rapid transition to online learning. Nonetheless, looking beyond this crucial application, Cross-Reality learning spaces are a promising aspect of the future of engineering education, vital to actively shape this future. require more formal, intentional means of oles involved, as this can help students

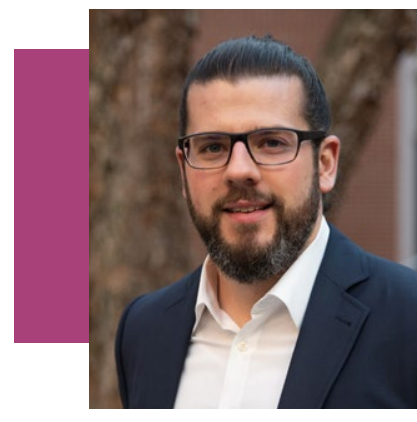

\section{Behind the Research}

\section{Dr Dominik May}

E: dominik.may@uga.edu T: +17065429626 W: https:///www.engineering.uga.edu/people/

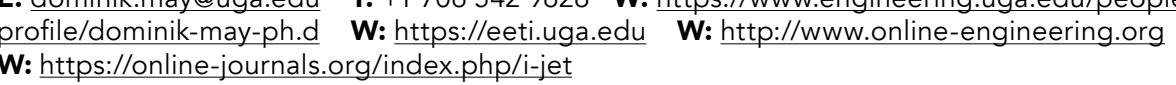
online labs successfully cultivated the lab activities and interface. Online guidelines can provide an environment the environments remains in online important component of the overall Education Transformation Institute's (EET)

Research Objectives

Dr Dominik May focuses on online laboratories and Cross-

\section{References}

May, D., Morkos, B., Jackson, A., Hunsu, N., Ingalls, A., \& Ens on und Cross-Reality. In C. Terkowsky, D. May, S. Frye, T. Hochschullehre - Didaktik, Digitalisierung, Organisation, 13-34. Bielefeld: wbv Publikation. (translated document) May, D. (2020). Wiecross Reality die Hochschule thre verande
kann und wird. Hochschulforum Digitalisierung (HFD) online blog, 2020. Available at: https://hochschulforumdigitalisierung.
de/de/blog/wie-cross-reality-die-hochschullehre-veraendern- May, D. (2020). Cross Reality Spaces in Engineering EducationOnline Laboratories for Supporting International Student
Collaboration in Merging Realities. International Journal of Online and Biomedical Engineering, 16(103), 4-26.
- Devine. R. P. \& May, D. (2020). Effect of S Simulated Laboratory Intervention on Biological Engineering Student Motivation A Case Study. Paper presented at the
International Conference on Remote Enginering International Conference on Remote Engineering and Virtual
Instrumentation (REV "Cross Reality and Data Science in Engineering", Athens, Georgia, USA. - Devine R., May D. (2021). Work in Progress: Pilot Study for Biological Engineering Students. In: Auer M. May D. (eds) Cross
Reality and Data Science in Engineering. REV 2020. Advances 52575-0 35 [Accessed 5th August 2021] - Al Weshah A., Alamad R., May D. (2021). Work-in-Progress Using Augmented Reality Mobile App to Improve Studen
Skills in Using Breasbord Engineering Course. In: Auer M., May D. (eds) Cross Reality and Data Science in Engineering. REV 2020. Advances in Intelligent Systems and Computing, Springer, Cham. 1231,
313-319. Available at: httrs://doi.org/10.1007/978-3-03052575-0_25 [Accessed 5th August 202 Li, R., Morelock, J. R., \& May, D. (2020). A Comparative Study of An Online Lab Using Labsland and Zoom during COVID-19.
Advances in Engineering Education, 8(4) 1-10 Available at: Advances in Engineering Education,
https://advances.asee.org/a-comparative-study-of-an-online-
lab-using-labsland-and-zoom-during-covid-19/ [Accessed 5th
August 2021] Beyete Jr, F. R. (under review). Rapid Transition of Traditionally
Hands-On Labs to Online Instruction in Engineering Courses. Lernen im Labor: Labordidaktische Ansätze zwischen Handsde/de//logo//ie-cross-reality-die--hochsch in Intelligent Syltems and Computing, Springer, Cham. 1231 measures to address them. For

\section{Detail}

Dominik May

University of Georgia
College of Engineering, Engineering
Education Transformations Institute

Education Transformations Institute
$2105 E$ Driftmier Engineering Center

2105E Driftmier Engineering
597 D.W. Brooks Drive

Bio
Dr May is an Assistant Professor in the Engineering Education development, introduction, practical use, and educational value of online laboratories and Cross-Reality learning spaces in engineering instruction. II his work, he focuses on developing broader
educational strategies for the design and use of virtual engineering equipment, putting these into practice and providing the evidence
base for further develooment efforts. Dr May is President of the base for further development efforts. Dr May is President of the
International Association of Online Engineering (IAOE), serves International Association of Online Engineering (IAOE), serves
as Editor-in-Chief for the International Journal of Emerging Technologies in Learning (iJETT, and works as guest editor
special issues of international journals in education. Funding
- German Federal Ministry of Education and Research
- American National Science Foundation

Collaborators
- The EAGER

- The EAGER project and online lab research: Nathaniel Hunsu, University of Georgia, USA) Co-founder \& CEO, USA) Tobias Haertel, Tobias ortelt, and Silke Frye (all TU Dortmund Online Engineering, AT): Isa Jahnke, (University of Muenster, Cologne, GER); Gustavo R. Alves (IInstituto Politecnico do Porto,
PT): Alexander Kist (University of So thurn Oleensland

Personal Response

What is the most important piece of advice that you would give to instructors using Cross-Reality learning spaces?

My advice to instructors would be threefold: Embrace the
opportunities the new technologies offer to your teaching and the classroom with an open mind. This might require stepping outside introduce new approaaches and technologies with respect to the course
goals and the intended learning outcomes. Don't use online labs as an end in titself, but only if they help you reach your goals. And finally,y thechnology, the students, and yourself. New approaches might not work at tirst but
improve over time, which is normal. However, students are typically very patient as long as you are transposent
strategies and even potential failures. Athens, Georgia 30602
United States Trudgen, Adel Al Weshah, Kyle Johnsen, and Joachim Walther (all
Teshor GER); Valerie Varney and Anja Richert (Technical University PT); Alexander Kist (University of Southern Queensland, AUS),
Stephanie L. Moore (University of New Mexiko, USA) 